\title{
RAINFALL FORECASTS, WEATHER AND WAGES OVER THE AGRICULTURAL PRODUCTION CYCLE
}

\author{
Mark R. Rosenzweig \\ Christopher Udry \\ Working Paper 19808 \\ http://www.nber.org/papers/w19808 \\ NATIONAL BUREAU OF ECONOMIC RESEARCH \\ 1050 Massachusetts Avenue \\ Cambridge, MA 02138 \\ January 2014
}

We thank Nirav Shah for excellent research assistance and Seema Jayachandran for comments. The views expressed herein are those of the authors and do not necessarily reflect the views of the National Bureau of Economic Research.

NBER working papers are circulated for discussion and comment purposes. They have not been peerreviewed or been subject to the review by the NBER Board of Directors that accompanies official NBER publications.

(C) 2014 by Mark R. Rosenzweig and Christopher Udry. All rights reserved. Short sections of text, not to exceed two paragraphs, may be quoted without explicit permission provided that full credit, including (C) notice, is given to the source. 
Rainfall Forecasts, Weather and Wages over the Agricultural Production Cycle Mark R. Rosenzweig and Christopher Udry

NBER Working Paper No. 19808

January 2014

JEL No. J2,J31,J43,O1,O13,Q12

\begin{abstract}
$\underline{\text { ABSTRACT }}$
We look at the effects of rainfall forecasts and realized rainfall on equilibrium agricultural wages over the course of the agricultural production cycle. We show theoretically that a forecast of good weather can lower wages in the planting stage, by lowering ex ante out-migration, and can exacerbate the negative impact of adverse weather on harvest-stage wages. Using Indian household panel data describing early-season migration and district-level planting- and harvest-stage wages over the period 2005-2010, we find results consistent with the model, indicating that rainfall forecasts improve labor allocations on average but exacerbate wage volatility because they are imperfect.
\end{abstract}

Mark R. Rosenzweig

Department of Economics

Yale University

Box 208269

New Haven, CT 06520

and NBER

mark.rosenzweig@yale.edu

Christopher Udry

Economic Growth Center

Yale University

Box 208269

New Haven, CT 06520

and NBER

udry@yale.edu 
In (Rosenzweig and Udry 2013) we showed that investments by Indian farmers in the July -August planting stage were significantly affected by the long-range kharif-season monsoon rainfall forecast issued by the Indian Meteorological Department (IMD) in late June. We also found that the profitability of those investments were highly sensitive to the realization of rainfall over the season, so that the forecasts enhanced average profits but contributed to profit volatility. In this article we examine the effects of the forecast and rainfall on planting- and harvest-stage agricultural wage rates. Prior research on the effects of rainfall on agricultural wage rates (e.g. Jayachdran, 2006; Kaur, 20012) have examined the effects of rainfall on seasonal average wages without attention to the timing of investment and labor-supply/migration decisions within the season. This neglect is potentially important, as wages in the planting stage are relatively unaffected by rainfall, but may be affected by rainfall forecasts, and the effects of rainfall realizations on harvest-stage wage rates may be affected by whether or not the rainfall forecast predicted good or bad weather for the season.

To analyze the interactions between rainfall forecasts and weather realizations on wages over the crop-cycle we first construct a simple general-equilibrium model of the agricultural labor market which is attentive to the sequential nature of agricultural production. In the first period prior to the full realization of rainfall, farmers choose agricultural inputs based on a forecast of subsequent rainfall while landless households decide whether to remain in the village or to out-migrate. We thus focus on the ex ante migration decision, in contrast to the prior literature that has examined ex post labor supply (Kochar, 1997) and ex post migration responses to rainfall shocks (Morten, 2013). In the second period of the model, the rainfall shock is realized and farmers profit-maximize, hiring the labor that has remained in the village given their sunk planting-stage investments. The model indicates that a positive rainfall forecast has an ambiguous effect on planting-stage wages, depending on the strengths of investment and 
migration responses, but can have a negative effect on harvest-stage wages if realized rainfall is low.

Based on the model, we estimate the effects of the IMD forecast on planting-stage migration decisions using household panel data and the effects of the forecast and rainfall realizations on planting- and harvest-stage wages using Indian district-level data on activity- and month-specific wages and district-level monthly rainfall data covering the period 2005-2010. In putting these data together, we uncover some of the pitfalls of using existing district-level wage and rainfall data. The estimates indicate that a forecast of above-average rainfall leads to reduced village out-migration, especially by men, and to a small but statistically significant overall decline in planting-stage wages. The positive forecast, as indicated by the model, also exacerbates the negative impact of adverse weather on harvest-stage wages. Thus, rainfall forecasts appear to improve the allocation of labor across space when they are correct but also increase inter-annual wage volatility as a result of being imperfect. We also show that the National Rural Employment Guarantee Act (NREGA), introduced in a limited set of districts in 2007 and then in all districts by 2010 , helps moderate this volatility.

\section{Rural Labor Markets with Forecasting}

In this section we provide a simple model of rural labor markets when informative forecasts of seasonal weather are available. Consider a set of identical farmers. Farm output is $h_{s}\left(x_{0}, x_{1}\right)$, where $x_{0}$ is the quantity of planting stage labor, $x_{l}$ is the quantity of harvest-stage labor and $s \in\{g, b\}$ is the weather realization. Planting-stage labor is chosen before $s$ is realized; harvest-stage labor after. We abstract from other inputs (and suppress the land input, since it is identical across farmers). Assume that $h_{b}\left(x_{0}, x_{1}\right)<h_{g}\left(x_{0}, x_{1}\right)$ and $\frac{\partial h_{b}\left(x_{0}, x_{1}\right)}{\partial x_{t}}<\frac{\partial h_{g}\left(x_{0}, x_{1}\right)}{\partial x_{t}}$ for $t \in\{0,1\}$. In addition, we assume that planting- and harvest-stage labor are complements and that 
this complementarity increases is good weather $\frac{\partial^{2} h_{g}\left(x_{0}, x_{1}\right)}{\partial x_{0} \partial x_{1}}>\frac{\partial^{2} h_{b}\left(x_{0}, x_{1}\right)}{\partial x_{0} \partial x_{1}}>0$. A forecast $F \in\{G, B\}$ is released before $x_{0}$ is chosen. Farmers have access to savings/credit markets, but we assume that there is no insurance available. After the forecast is made, farmers choose labor inputs $\left(x_{0}, x_{1 g}, x_{1 b}\right)$ and saving/borrowing $(a)$ to maximize

$$
u\left(c_{0}\right)+\operatorname{prob}(b \mid F) u\left(c_{1 b}\right)+(1-\operatorname{prob}(b \mid F)) u\left(c_{1 g}\right) .
$$

Conditional on the forecast, the farmer's budget constraints are

$$
\begin{gathered}
c_{0}=Y-w_{0}(F) x_{0}-a \\
c_{1 s}=h_{s}\left(x_{0}, x_{1}\right)-w_{1 s}(F) x_{1}+r a,
\end{gathered}
$$

where we have made the possible dependence of wages on the forecast explicit. Both output and consumption are valued at price 1 .

If state $s$ is realized in period 1 after a forecast of $F$ in period zero we have separability in the choice of $x_{1}$ which can be summarized by

$$
x_{1}\left(x_{0}, s, w_{1 s}(F)\right) \equiv \underset{x_{1}}{\arg \max } h_{s}\left(x_{0}, x_{1}\right)-w_{1 s}(F) x_{1} .
$$

The concavity of $h_{s}($.$) implies that x_{1}\left(x_{0}, s, w_{1 s}\right)$ is decreasing in $w_{1 s} . x_{1}\left(x_{0}, g, w\right)>x_{1}\left(x_{0}, b, w\right)$ because the marginal product of harvest labor is higher in good weather. Complementarity between planting- and harvest-stage labor implies $x_{1}\left(x_{0}^{h}, s, w\right)>x_{1}\left(x_{0}^{l}, s, w\right), \forall x_{0}^{h}>x_{0}^{l}, s \in\{g, b\}$. We have a mass 1 of identical farmers demanding labor, so the aggregate demand for harveststage labor in the village is simply $x_{1}\left(x_{0}, s, w_{1 s}(F)\right)$. Turning to the planting-stage, Rosenzweig and Udry (2013) show that $x_{0}\left(\mathrm{G}, w_{0}, w_{1 g}, w_{1 b}\right)>x_{0}\left(\mathrm{~B}, w_{0}, w_{1 g}, w_{1 b}\right) . x_{0}$ is strictly declining in each of the three wages. Farmers are identical, so aggregate planting-stage labor demand is simply $x_{0}\left(F, w_{0}, w_{1 g}, w_{1 b}\right)$ 
Labor is supplied by a mass 1 of landless laborers. After the forecast, the landless choose to migrate out of the village or not $(m \in\{0,1\})$. If they choose to migrate, they earn the wage at the place to which they migrate in both the planting and the harvest-stage; if they choose not to migrate they supply 1 unit of labor to the village labor market. Landless choose $m$ to maximize (1) subject to

$$
\begin{gathered}
c_{0}=Y+m w_{m}+(1-m) w_{0}(F)-a \\
c_{1 s}=m w_{m}+(1-m) w_{1 s}(F)+r a
\end{gathered}
$$

where $w_{m}$ is the net wage from migration, which is known and the same in period 0 and any state of period 1 . The landless have a distribution of net wages from migration given by $H\left(w_{m}\right)$.

There is a critical $\bar{w}_{m}=\Omega\left(F, w_{0}, w_{1 g}, w_{1 b}\right)$ such that all landless with $w_{m} \geq \bar{w}_{m}$ migrate and all others do not (in parallel to the cultivators, we are assuming that all landless have the same $Y$, so we suppress the dependence of $\bar{w}_{m}$ on $Y$ ). $\Omega$ is increasing in each of the wages. If in equilibrium $w_{1 g}>w_{1 b}$ then $\Omega\left(G, w_{0}, w_{1 g}, w_{1 b}\right)>\Omega\left(B, w_{0}, w_{1 g}, w_{1 b}\right)$, because of the higher probability of good weather occurring conditional on a forecast of good weather. Labor supply in the planting-stage and in the good and bad states of the harvest-stage is identical and equal to $H\left(\bar{w}_{m}\right)$.

The equilibrium set of wages $\boldsymbol{w}(F)=\left\{w_{0}(F), w_{1 g}(F), w_{1 b}(F)\right\}$ satisfies

$$
\begin{aligned}
& H\left(\Omega(F, \boldsymbol{w}(F))=x_{0}(F, \boldsymbol{w}(F))\right. \\
& H\left(\Omega(F, \boldsymbol{w}(F))=x_{1}\left(x_{0}, g, w_{1 g}(F)\right)\right. \\
& H\left(\Omega(F, \boldsymbol{w}(F))=x_{1}\left(x_{0}, b, w_{1 b}(F)\right)\right.
\end{aligned}
$$


Equilibrium harvest-stage wages are always higher in good than bad weather: for $F \in\{G, B\}$, $w_{1 g}(F)>w_{1 b}(F)$. The complementarity between planting- and harvest-stage (which is stronger in better weather) ensures that $w_{1 g}(G)-w_{1 b}(G)>w_{1 g}(B)-w_{1 b}(B)$.

The effect of the forecast on planting- and harvest-stage wages can be ambiguous because of the potential migration response to a good vs. bad forecast. The reservation migration wage increases with a forecast of good weather, because the local harvest-stage wage is higher in good weather. Suppose that there is a small migration response to this change in the reservation wage: $H(\Omega(B, \boldsymbol{w}(B))) \approx H(\Omega(G, \boldsymbol{w}(B)))$. Then, because $x_{0}(G, \boldsymbol{w})>x_{0}(\mathrm{~B}, \boldsymbol{w})$ and $x_{1}\left(x_{0}, s, w_{1 s}\right)$ is increasing in $x_{0}$, equilibrium wages are higher with a forecast of good weather. But the reverse can be true if the migration response to the forecast is sufficiently strong.

The public works opportunities provided by NREGA are modelled as a wage floor. The most interesting case is when equilibrium wages have the following pattern in the absence of NREGA: $w_{1 g}(F)>w_{0}(F)>w_{1 b}(F)$. Now suppose NREGA introduces a wage floor $(\underline{w})$. Our model implies that the effect of increasing $\underline{w}$ depends on when this floor binds. If it binds only in the harvest-stage if the rainfall is poor, then, since out-migration declines as $\underline{w}$ increases and planting-stage labor demand declines with harvest-stage wages, both the planting-stage wage and the harvest-stage wage if there is good rainfall decline as NREGA comes into effect. In contrast, if $\underline{w}$ is greater than the planting-stage wage, then the planting-stage wage increases with NREGA.

In our empirical work, we examine four facets of this model. First, we examine the migration response during the planting-stage to the IMD forecast. Second, we quantify the equilibrium response of district-level planting-stage wages to the forecast. Third, we ask if the effect of rainfall shocks on district-level harvest-stage wages varies according to the forecast. In 
particular, is the negative effect of a bad rainfall shock particularly severe after a forecast of a good monsoon? Finally, we look at the effect of NREGA on planting- and harvest-stage wages.

\section{Data}

Analyzing stage-specific responses to forecasts and rainfall realizations requires data that provide information by either agricultural production stages or by month. In Rosenzweig and Udry (2013) we used the International Crop Research Institute for the Semi-Arid Tropics Village Level Survey Data (ICRISAT VLS), which provides high frequency information on agricultural inputs by date and operation for six villages over the period 2005-2011. These data also provide information on the out-migration of household members included in the survey. For the purposes here of studying ex ante out-migration, we focus on out-migration between July 1 and August 15 - after the Indian Meteorological Department (IMD) June forecast but prior to the full realization

of rainfall. Unfortunately, the surveyors did not adhere to the monthly survey design in 2007 and 2008, so we have five years of migration information for the six villages. Out-migration in the early months of the kharif (June-October) season is non-trivial for prime-age males. As seen in the top panel of Table 1, almost 16\% of males age 15-39 migrated in July-August. Female ex ante migration is one-third that of male migration. The sample we use for the analysis of migration includes all household members who participated in the labor market during the kharif season. Because of the different migration rates of men and women, we also analyze the determinants of migration separately by gender.

For the empirical analysis of agricultural wage rates we also need wage rates by operational stage. The Directorate of Economics and Statistics within the Indian Ministry of Agriculture provides district-level daily agricultural wages by month, "activity," and gender. Three activities are relevant to our analysis - "sower" and "ploughman" for the planting stage and "reaper and harvester" for the harvest stage. Our criteria for choosing wages was to select 
male wages for sowers and ploughman in the month of June and July and male harvesters for September and October for the years 2005-2010. Unfortunately, many of the districts had missing information for these month and activity classifications. To maximize sample size, we constructed June/July planting-stage wages by first selecting ploughmen wages in those months, then if this category was missing selecting the wage rates of sowers and then if this category was missing for the relevant months we used the wages for "other agricultural labor." The majority of wages for the planting-stage were for ploughmen. For the September/October harvest period, we selected harvester/reaper wages as a priority and then the wages for other agricultural operations in those months if wages were missing for that activity. ${ }^{1}$ All wages are deflated by the CPI for agricultural workers, using 2005 as the base year.

The standard rainfall data set for monthly Indian district-level rainfall is the Terrestrial Air Temperature and Precipitation compiled by Cort J. Wilmott and Kenji Matsuura, which covers the period $1950-2010$. While rainfall is provided for a 0.5 by 0.5 degree grid of points across India, which can be matched to the centroid of each of over 600 Indian districts, the source of the rainfall information comes from only 81 weather stations maintained by the National Center for Atmospheric research (NCAR). The district-level rainfall data is thus spatially interpolated. This interpolation introduces noise. To minimize the effects of measurement error, we initially selected districts that were within 100 miles of the NCAR weather stations (65 districts). However, because of the problem of missing wage information, to increase the number of districts we added additional districts. The final data sets for analysis

\footnotetext{
${ }^{1}$ Jayachrandran (2006) and Kauer (2012) used the district-level male agricultural wage series assembled by Robert E. Evenson and James W. McKinsey, Jr. from the same monthly wage data we use, and available in the World Bank India Agricultural and Climate data. This series does not distinguish wages by stage of operation, providing only one average wage observation per year that weights the months of June and August more heavily and also selects ploughman as a priority activity. Because June operations and ploughing in particular cannot be affected by rainfall over the full agricultural season, this wage series will be less sensitive to weather realizations than will a wage series focusing on the harvest stage. In our analyses of planting-stage and harvest-stage wage rates we included dummy variables indicating activity-type for the relevant months. These were not statistically significant.
} 
consisted of 106 districts and 387 observations for planting-stage wages and 95 districts and 337 observations for harvest-stage wages.

Using the rainfall data, we constructed for each district and year the ratio of actual rainfall in the July-September period over its 60-year historic mean. We classify a bad rainfall shock as one in which this measure is below one. We also appended to each observation the June area- and year-specific IMD forecast and created a dummy variable for each district/year indicating whether or not NREGA had been implemented in the district.

The bottom panel of Table 1 provides descriptive statistics for these data. As can be seen, the average distance of an NCAR weather station to a district is over 82 miles. As a consequence, in our wage specifications we examine whether the estimated rainfall shock effect on harvest wages is attenuated by weather station distance. A key point of our analysis is that the determinants of planting- and harvest-stage wages are not the same. In our data sets, while the average levels of the harvest and planting-stage wages are similar, they display distinctly different variability across years. This is indicated in Figure 1, which plots the ratio of harvest to planting-stage wages by year for the districts and years in which both stage-specific wages are available.

\section{Results}

Table 2 reports village fixed-effect estimates of the effect of the IMD long-range forecast on planting-season migration in the ICRISAT VLS survey. In column one, the point estimate implies that a one standard deviation increase in forecasted rain leads to a 0.7 percentage point reduction in migration, from a base level of 9 percent of the population. ${ }^{2}$ Columns 2 and 3 provide estimates by gender. The responsiveness of migration to the forecast is stronger for men than for women. A one standard deviation increase in forecasted rain leads to a decline of 1.1

\footnotetext{
${ }^{2}$ The effect of forecasted rain on migration is robust to controls for realized rainfall over the entire monsoon, or for realized rain in June and July (not shown). 
percentage points in male seasonal migration (from a base of 16 percent). Female seasonal migration is insensitive to forecasted rain. Female seasonal migration is also not associated with age, and female migration declines with education, in contrast to the pattern observed for men.

In Table 3 we examine the relationships between the IMD forecast and realized rainfall for equilibrium planting- and harvest-stage agricultural wages using the district-level data. The district fixed effect estimates indicate that there is a small, but precisely-determined decline in the planting-stage wage with increases in forecasted rainfall. A one standard deviation increase in forecasted rainfall leads to a 2 percent decline in the planting-stage wage. This is consistent with the migration response to forecasted rain that we observe in Table 2.

The planting-stage wage also increases with rainfall shocks. A one standard deviation increase in rainfall above the long-term average increases planting-stage wages by 5.6 percent. However, this relationship declines in the distance between the district centroid and the nearest NCAR weather station. The point estimates indicate that there is no correlation between the rainfall shock and planting-stage wages for a district 100 miles from the nearest station. The estimates also indicate that the implementation of the National Rural Employment Guarantee Act increased planting-stage wages by about 9.6 percent. Thus the NREGA wage is sufficiently high that it binds in the planting-stage.

The model suggests that harvest-stage wages are differentially sensitive to the IMD forecast, depending upon realized rainfall. This is shown in column 2 of Table 3. On average, harvest-stage wages move little with the IMD forecast, which is consistent with the migration response to the forecast seen in Table 2. However, increases in forecasted rainfall lead to declines in the harvest-stage wage if a bad rainfall shock is realized. This effect occurs both because the forecast of more rainfall increases labor supply by reducing seasonal migration away 
from the village, and because the bad rainfall shock reduces harvest-stage labor demand by cultivators.

As we observed with planting-stage wages, the estimated relationship between rainfall shocks and harvest-stage wages declines with the distance between the district and the nearest NCAR rainfall station. Implementation of NREGA is also associated with increases in harvest-stage wages, particularly in years with bad rainfall shocks, as expected.

\section{Conclusion}

Informative rainfall forecasts permit welfare-improving anticipatory migration. This complements the finding of Rosenzweig and Udry (2013) that forecasts improve average profits of cultivators. The supply of and the demand for stage-specific agricultural labor depend on forecasts of seasonal rainfall. As a consequence, equilibrium stage-specific wages for agricultural labor are sensitive to these forecasts. The response of harvest-stage wages to forecasted rainfall, however, varies depending upon realized rainfall for the season. The availability of rainfall forecasts creates a new risk for the landless, even if they have rainfall insurance. $^{3}$ A forecast of good rainfall (which reduces out-migration of labor from the village) followed by a realization of adverse weather generates a sharper drop in the harvest-stage wage than would be realized were no forecast available. Hence even if perfect (basis-risk free) weather index insurance existed, there would still be a missing market for forecast insurance. Our results indicate that NGEGA, in part, fills this function by raising harvest-stage wages particularly in bad weather states.

\section{References}

Jayachradran, Seema. 2006. "Selling Labor Low: Wage Responses to Productivity Shocks in Developing Countries." Journal of Political Economy 114 (3): 538-575.

\footnotetext{
${ }^{3}$ Mobarak and Rosenzweig (2013) examine the effects on agricultural wages of rainfall insurance purchased by cultivators and/or the landless.
} 
Kaur, Supreet. 2012. "Nominal Wage Rigidity in Village Labor Markets." unpublished.

Kochar, Anjini. 1997. "Smoothing Consumption by Smoothing Income: Hours-of-Work Responses to Idiosyncratic Agricultural Shocks in Rural India," Review of Economics and Statistics 81(1): 50-61.

Morten, Melanie. 2013. "Temporary Migration and Endogenous Risk Sharing in Village India." unpublished.

Mobarak, Ahmed Mushfiq and Mark R. Rosenzweig. 2013. "Risk, Insurance and Wages in General Equilibrium," Yale University Economic Growth Center Discussion Paper No. 1035.

Rosenzweig, Mark R. and Christopher R. Udry. 2013. "Forecasting Profitability." NBER Working Paper No. 19334. 
Table 1

Descriptive Statistics, by Data Set

\begin{tabular}{lcc}
\hline \hline \multicolumn{1}{c}{ Variable } & Mean & SD \\
\hline \multicolumn{1}{c}{ ICRISA VLS India, 2005-2011 } & \\
\hline Planting-stage migration rate, males 15-39 & .157 & .364 \\
Planting-stage migration rate, females 15-39 & .0467 & .211 \\
Age & 33.3 & 18.8 \\
Schooling (years) & 5.37 & 4.46 \\
Forecast & 96.5 & 2.36 \\
\hline \multicolumn{1}{c}{ District Male Agricultural Daily Wages, 2005-2010 } \\
\hline Planting-stage wage (2005 Rs.) & 71.6 & 32.2 \\
Harvest-stage wage (2005 Rs.) & 73.0 & 29.4 \\
Rainfall shock (relative to 60-year mean) & 1.04 \\
Bad rainfall shock (below mean) & .347 & .293 \\
Distance from nearest NCAR weather station (miles) & 82.1 & .477 \\
Forecast & 95.1 & 59.7 \\
National Rural Employment Guarantee Act (NREGA) in place & .615 & 4.12 \\
\hline
\end{tabular}

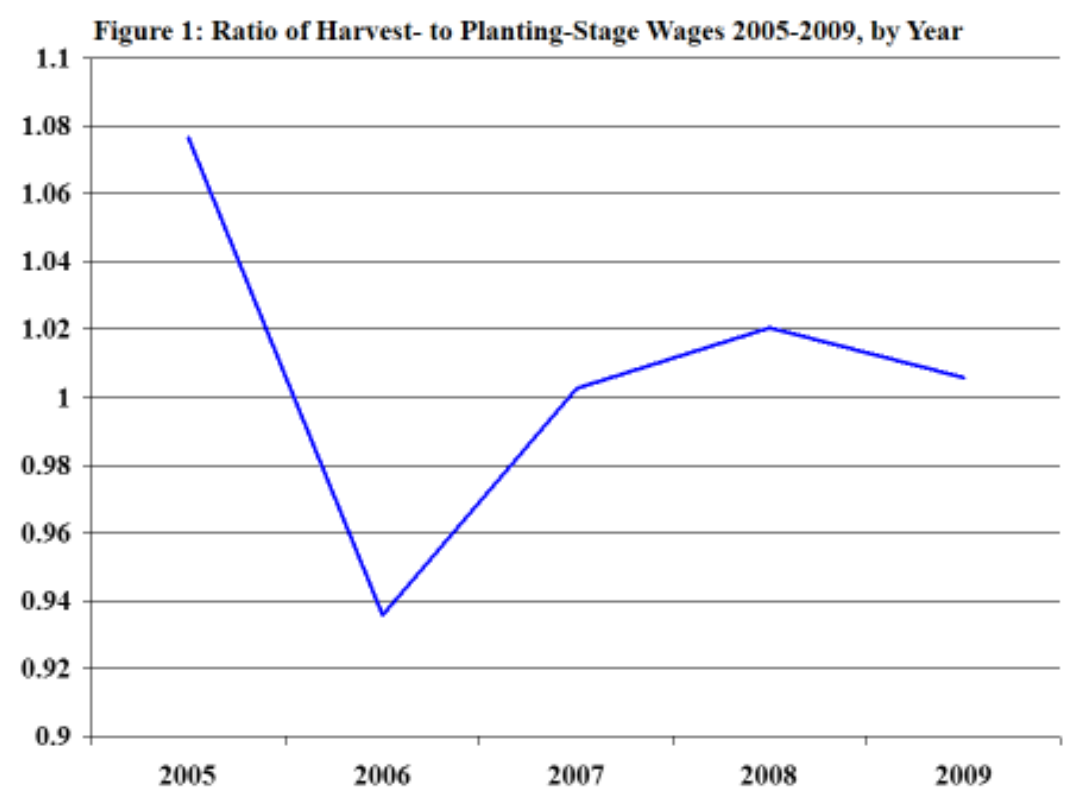


Table 2

Village Fixed-Effects Estimates of the Determinants of Planting-Stage Out-Migration (ICRISAT VLS India: 2005-2011)

\begin{tabular}{lccc}
\hline \hline Variable & All Workers & Males & Females \\
\hline Forecast & -.00293 & -.00485 & -.000332 \\
& $(2.69)$ & $(2.68)$ & $(0.33)$ \\
Age & .000853 & .00141 & -.000195 \\
& $(1.32)$ & $(1.32)$ & $(0.32)$ \\
Age squared & -.0000194 & -.0000314 & -.0000683 \\
& $(2.38)$ & $(2.28)$ & $(0.91)$ \\
Schooling & .00711 & .0118 & -.00184 \\
& $(10.0)$ & $(10.9)$ & $(2.47)$ \\
Male & .0557 & - & - \\
& $(9.58)$ & & 2,994 \\
$\mathrm{~N}$ & 6,501 & 3,507 & \\
\hline
\end{tabular}

Absolute values of $t$-ratios in parentheses.

Table 3

Village Fixed-Effects Estimates of the Determinants of Male Daily Wages, by Stage of Operation (Agricultural Wages of India, 2005-2010)

\begin{tabular}{lcc}
\hline \hline Variable & Log Planting-Stage Wage & Log Harvest-Stage Wage \\
\hline Rainfall shock & .192 & .056 \\
& $(3.09)$ & $(0.73)$ \\
Rainfall shock x distance to & -.00196 & -.00152 \\
weather station (miles) & $(2.56)$ & $(1.72)$ \\
Forecast & -.00622 & .000898 \\
& $(2.71)$ & $(0.30)$ \\
Forecast x & - & -.00109 \\
bad rainfall shock & & $(2.09)$ \\
NREGA in place & .096 & .0623 \\
& $(4.50)$ & $(1.76)$ \\
NREGA x bad rainfall shock & - & .0929 \\
N & 387 & $(1.78)$ \\
\hline
\end{tabular}

Absolute values of $t$-ratios in parentheses. 